\title{
Unmasking or demythologising medicine?
}

Ronald A Carson Department of Community Health and Family Medicine, College of Medicine, Univers of Florida, Gainesville, Florida, USA

\section{Editor's note}

The author, a teacher of medical ethics in America, agrees with much in the lectures ( $\mathrm{I}$ ). However he criticises among other points what he callsKennedy's 'pallid utilitarianism' and inadequate concern for t':e freedom of the individual. Although he agrees that medical ethics should not be taught by doctors he disagrees that it should be taught by 'outsiders'. The latter tend to be ignored or patronised by medical students. Instead medical ethics should be taught by 'resident aliens' - members of the medical faculty whose professional expertise and 'angle of vision' emanate from the humanities rather than from medicine.

Ian Kennedy's Reith Lectures for 1980 are aimed at 'unmasking medicine', with a view to changing it or at least imagining it changed. The lectures are an interesting mixture of reflection, proposition and call-to-action which seem likely however, to fail to accomplish their stated purpose of broadening the debate about medicine for reasons I shall spell out here.

There is much with which to agree in the lectures. 'Medicine is perceived and pursued in ways which do not best serve the needs of society', Kennedy argues. Medicine today is conceptually reductionist (another way of characterising the tunnel vision induced by disease theory) and symptom-responsive in practice-medicine by reflex, aimed at fixing parts. It is, in addition, an enterprise that is essentially hospital-based, oriented towards acute care, and increasingly dependent on innovative (and therefore rapidly outmoded and expensive) technologies. Christiaan Barnard is hero and Albert Schweitzer 'a somewhat ludicrous figure'. Medicine promises more than it can reasonably deliver and is widely believed capable of doing even more. It is no wonder, then, that modern medicine is surrounded by disquiet and even dissatisfaction.

What if, Kennedy muses, medicine took a different form? That new form, in his view, would be primarily preventive in orientation and, in terms of resource distribution, would favour low-cost, high-yield practices. 'There are perfectly respectable ethical theories which in the context of harsh choices ... allow for conduct which will benefit the larger or more worthy number even if this inevitably means the others may suffer'. One can admit the attractiveness of such a proposal a $\overrightarrow{\mathrm{Ad}}$ yet question Kennedy's appeal to a pallid utilitarianism by way of justifying it.

A number of points in the lectures elicit m $\mathrm{m}$ d disagreement. In the third lecture Kennedy proposes a blueprint for action embodying an affirmation. the two principles from which, in his view, a sound and just health care system should derive; that need should be the only criterion of access to care; a that the system should be supported by funds raised according to citizens' ability to contribute.

Changing the health care system for better is nt a matter of choosing between interventionist asid preventionist approaches to medical care, boit rather of deciding how much of each society needs and can afford, and then striking a proper balan\&. Kennedy's view, with which I have no quarrel, $\overrightarrow{\text { is }}$ that the balance should be tipped towards prevention of illness and accidents and the promotion of health.

Before political action can effectively take place, political education is necessary. People must leæn to value illness prevention. And the professional b $\mathrm{g}$ t situated to initiate this learning is the general pratitioner, the primary care physician. 'If GPs wexe more adequately prepared for the real health needs of their patients which are as much to do with social problems as with particular diseases, then the beginnings of the movement towards better heaith could emerge. ... . No one is better placed to gaughe the social pressures and problems of the day and pass the news on up the line and no one is better placed to act as an educator for better health abd pass the word down the line'. One can imagine how GPs might be better educated to the general hea needs of their patients. But in view of the relative powerlessness of the GPs to effect changes in the health care system which they know from first hand experience to be desirable, the suggestion that relaying their experience 'up the line' (presumaby to adherents of the prevailing 'fix-it' values) seets politically naive.

In urging upon us strategies of prevention, Kennedy barges ahead where a judicious approach might have gained a wider audience for his views. He may be right to call for a social commitment $\Phi_{0}$ education for health in schools, in the home, and tiRe work place; he is surely right to insist on education to combat the spread of misinformation, kia advertising, regarding the substances and practiess 
known to be detrimental to health. But for all his stated desire that more attention be given to values in medicine, he obscures an otherwise sound idea by blinking at such important distinctions as that between educating and enforcing, and by failing to credit the complexity of fashioning policies that persuade people but stop short of punishing them for their 'unhealthful behaviours'. 'Of course it is fair to note that there are those who ... . will argue that there is a limit to the extent which government should-not can-interfere in the life of the individual'. There are those indeed! Kennedy weakly acknowledges some merit in arguments for the freedom of the individual, but the paragraph he devotes to such arguments has the effect of brushing them aside.

I find myself in moderate disagreement with the proposals contained in the lectures for dealing with ethical problems associated with medicine. Most medical decisions, Kennedy argues, are moral decisions in the making of which doctors have no special expertise. Acting on a diagnosis to devise a course of treatment requires physicians to make judgments about the meaning of life, death, disability and suffering which are not theirs to make. '[Doctors] seem to operate on some kind of automatic pilot when it comes to matters of ethics'. $\mathrm{He}$ takes doctors to task for their ambivalence in making moral judgments and implies that they fudge fundamental values, such as trust, in selfserving ways. My own view is that this ambivalance is a subtle acknowledgement by doctors of their uneasiness in making moral judgments and, as such, is to be welcomed. Just as surely as we do not want doctors controlling our lives, we want them to be more than technicians of our bodies.

There is an attractive tidiness to the claim that 'we should all be given a chance to know and to decide on the basis of clear and agreed upon principles'. But I do not see how we all would arrive at such a consensus. One remedy for the problem of generalisation of physician expertise might be to empower people (prospective patients) by making them knowledgeable about their bodies and about the limits of medicine. Perhaps this is part of what Kennedy means by health promotion and illness prevention, but he does not say so.

Another remedy, one which the author does recommend, is to place greater emphasis on the humanities in medical education. (He seems to mean by 'humanities' chiefly ethics. This is unfortunate in that education for medicine can be considerably enriched by the skilled introduction into the curriculum of perspectives from such fields as history, literature, and philosophy.) This is a splendid idea, though I take issue with Kennedy's insistence that ethics be taught by an outsider, 'someone not deafened by the rhetoric of medicine'. It goes without saying that the humanities should be taught by those with expertise in one or another of the constituent disciplines of the humanities. And certainly one of the aims of introducing perspectives from the humanities into medical education is to encourage students to reflect critically on the precepts of their profession - a tall order indeed in a professional school which, by design, not only trains students to be good practitioners but also socialises them into a profession. The person best suited to this task is not an outsider, but a 'resident alien'-a professional from the humanities who subscribes to the fundamental aim of medical education to produce good doctors and who is part of the medical faculty but whose angle of vision and expertise emanate from the humanities. Like it or not, outsiders tend either not to be able to get the attention of the students ("What do the humanities have to do with my medical education ?') or to be patronised and not taken seriously ('If we must do this, let's get it over with so that we may get back to what really matters'). Either way, the humanities taught by an outsider remain peripheral to medical education.

The major shortcomings in the lectures are, in my view, to be found in the sections on the rhetoric of medicine and on the consumerist approach to medical care. Kennedy analyses prevailing concepts of health and illness, pointing up the centrality of values in each. He criticises our habit of permitting physicians virtual monopoly of authority for confirming the presence of health and illness. If illness and health are fundamentally moral rather than technical notions, denoting conditions of ourselves (and not merely of our bodies), how does it follow that doctors, whose expertise lies in understanding the (mal)functioning human body, are the appropriate arbiters of human health and illness?

When he shifts his analysis to the predominant conceptual framework of medicine-the disease model of medicine (notice, not the medical model of disease)-Kennedy finds that framework too redolent with values. The consequences of overlooking the moral dimensions of the disease model of medicine are no less far-reaching than are those of ignoring the moral character of our ways of construing health and illness. The generalising of medicine's experience in successfully diagnosing and treating many infectious diseases has, Kennedy argues, 'induced a sort of medical tunnel vision' which overlooks 'the great complexity of each of us'. This analysis is interesting but not incisive.

As common sense and our best theorists tell us, health, illness and disease are descriptive and evaluative terms. 'Health' denotes a condition of the body (broadly conceived so as to encompass spirit, soul, or mind) judged, according to the prevailing value system in a society, to be desirable. Being healthy means being fit, being able to go and do when you want. As physician-poet John Stone puts it, 'Health is whatever works, and for as long.' Illness is an experience of dis-ease which contrasts a 
person's condition with accepted notions of what it means to be healthy. A disease is also a deviation from a norm but one that applies to bodily organs and organ-systems rather than to persons. A disease becomes an illness only if it is involuntarily incapacitating. We exhibit in our various behaviours and lifestyles a wide range of interpretation of these concepts. Physicians too acknowledge variation, as is noticeable in the generous sprinkling of their diagnostic exchanges with such phrases as 'within normal limits'.

Choosing to call a set of symptoms or a syndrome a disease usually implies a commitment to medical intervention and the assignment of the sick role. What troubles Kennedy is that it is doctors rather than sick people themselves who do the choosing and assigning, with the result that sick people relinquish control over their bodies and their lives. Kennedy shows us how doctors view illness (as disease) but he has little to say about patients' perceptions of illness. This is a serious omission in view of his interest in redressing an imbalance in the doctor-patient relationship in favour of patients. 'Everything proceeds on the basis of the particular doctor's judgment. . . . Can't we have some more certain guarantees that our interests, as defined by us, may be allowed to prevail?' But is it our 'interests' that matter most in these relationships? I doubt it. People do not simply get sick. They feel ill. What is wanted is not a legal explication of the interests of patients but a phenomenological analysis of the experience of illness.

This last comment brings up the other major shortcoming of the lectures. 'In the practice of medicine the consumer is the patient. His interests, which consumerism would seek to assert, are those of self-determination and the power to participate responsibly in decisions made about his life'. This is the least adequate of the six discussions. It is intemperate ('consumerism is with us. The doctor has the choices only of accepting it willingly and cooperating, or of accepting it unwillingly.') and accusatory (doctors are 'hostile' and 'intransigent'). A little contentiousness can be a good thing for breaking a stalemate and moving stymied negotiations along. But Kennedy's provocations in this lecture seem gratuitous and are thus unlikely to provoke the broadening of the debate about medicine the author wants.

Kennedy's treatment of informed consent, one of the central principles of medical ethics, seems curiously abridged. He discusses it in the context of 'consumerism as litigation' and says erroneously that '[the doctrine of informed consent] is a product wholly of courts', a mechanism for compensating the injured in a country (the US) in which doctors' insurance is the only source of such compensation, there being no social welfare system (as in the UK). US courts have expanded the notion of negligence, Kennedy claims, in order to answer in a socially responsible way the question: Who should conts. pensate the victims? Granted that the author purpose in this final lecture was to set out a con sumer model of regulation which might set standares for and assess physician performance and proviee sanctions for performance which fails to measupe up, nonetheless, by limiting the discussion $\&$ f informed consent to legal considerations, he miss 8 another opportunity to enlarge the debate abog t medicine.

Informed consent is not a product of the courts: it is a central requirement undergirding the ther $\overrightarrow{55}$ peutic relationship (and, of course, the relation of human subjects to medical researchers as well). $\overrightarrow{3} t$ consists, simply stated (though it is not a simple notion), in a reasonable disclosure of information a physician to a patient on the basis of which t patient grants permission for a course of treatment to be undertaken or a procedure to be done. This exchange of information and permission, involving as it often does the entertaining of alternatives amd complex as it often is, is the very stuff of the doctor-patient relationship. Such exchange cultivates the bond of trust that makes healifg possible.

'Unmasking' seems an odd choice to denote the purpose of these lectures. The author's conce throughout is with 'the twin notions of responsbility and power in the context of the practice of medicine'. It is as much the mythology as the reality of modern medicine which troubles Kennech, a mythology of spectacular advances and miraculous cures. And the mythology is pernicious, not for intrinsic reasons, but because of its social and political implications. If people believe (and doctors do not divest them of the belief) that medicine can virtually always unlock illness and fend off death that doctors can cure just about whatever ails us $\frac{\bar{\sigma}}{\bar{\sigma}}$ then people will be considerably dependent on doctors. This dependence is deepened all the moipe when it is left to doctors to determine who is sigk and who well. 'Unmasking' suggests that modesn medicine is something other that it appears to be, and that tearing away the mask will reveal medicine as it really is. But the matter is not so simple, as Kennedy himself is clearly aware. For what the attempts (and ultimately fails to accomplish) is demythologising of medicine, a much more delicate and demanding task than unmasking in that entails separating out elements of the ethos of medical practice that have become part of its very fibre.

\section{Reference}

(I) Kennedy I. The Reith Lectures: Unmaskigg medicine. The Listener 1980 Nov 6, 13, 20, 27, Dec 4, II. All quotations are taken from this serios of lectures. 